\title{
Wastewater from Instant Noodle Factory as the Whole Nutrients Source for the Microalga Scenedesmus sp. Cultivation
}

\author{
Worawit Whangchenchom ${ }^{1}$, Wilai Chiemchaisri ${ }^{2}$, Paveena Tapaneeyaworawong, ${ }^{3,4}$, Sorawit Powtongsook ${ }^{3,4^{+}}$ \\ ${ }^{1}$ Interdisciplinary Graduate Program in Advanced and Sustainable Environmental Engineering (International Program), Faculty of Engineering, Kasetsart \\ University, Bangkok 10900, Thailand \\ ${ }^{2}$ Department of Environmental Engineering, Faculty of Engineering, Kasetsart University, Bangkok 10900, Thailand \\ ${ }^{3}$ National Center for Genetic Engineering and Biotechnology, National Science and Technology Development Agency, Pathumthani 12120, Thailand \\ ${ }^{4}$ Center of Excellence for Marine Biotechnology, Department of Marine Science, Chulalongkorn University, Bangkok 10330, Thailand
}

\begin{abstract}
Cultivation of microalgae using wastewater exhibits several advantages such as nutrient removal and the production of high valuable products such as lipid and pigments. With this study, two types of wastewater from instant noodle factory; mixed liquor suspended solids (MLSS) and effluents after sedimentation tank were investigated for green microalga Scenedesmus sp. cultivation under laboratory condition. Optimal wastewater dilution percentage was evaluated in 24 wells microplate. MLSS and effluent without dilution showed the highest specific growth rate $(\mu)$ of $1.63 \pm 0.11$ day $^{-1}$ and $1.57 \pm 0.16$ day $^{-1}$, respectively, in which they were significantly $(\mathrm{p}<0.05)$ higher than Scenedesmus sp. grown in BG11 medium (1.08 \pm 0.14 day $\left.^{-1}\right)$. Ten days experiment was also conducted using $2000 \mathrm{ml}$ Duran bottle as culture vessel under continuous light at approximately 5000 lux intensity and continuous aeration. It was found that maximum biomass density of microalgae cultivated in MLSS and effluent were $344.16 \pm 105.60 \mathrm{mg} / \mathrm{L}$ and $512.89 \pm 86.93 \mathrm{mg} / \mathrm{L}$ respectively and there was no significant $(\mathrm{p}<0.05)$ difference on growth to control (BG11 medium). Moreover, cultivation microalgae in wastewater could reduce COD in wastewater by $39.89 \%-73.37 \%$. Therefore, cultivation of Scenedesmus sp. in wastewater from instant noodle factory can yield microalgae biomass production and wastewater reclamation using photobioreactor simultaneously.
\end{abstract}

Keywords: Instant noodle factory, Microalgae cultivation, Scenedesmus sp., Wastewater

\section{Introduction}

Using microalgae for wastewater treatment has several benefits such as reducing nutrient loading, $\mathrm{CO}_{2}$ fixation, removal of heavy metal, production of high-value chemicals (algal metabolites) [1, 2]. Moreover, algal cultivation in wastewater had smaller carbon footprint in comparison with the cultivation in clean water, no secondary pollution, etc. [3]. With this study, wastewater from instant noodle factory which contains high residual nutrients was chosen as a new potential media for microalgae cultivation.

Recent studies on microalgae cultivation illustrated that several microalgae species can growth in wastewater using open systems or closed systems. Scenedesmus sp. is the green microalga widely used for nutrient removal and biomass production. Nitrogen and phosphorus removal efficiency by Scenedesmus sp. in artificial wastewater was 30\%-100\% [1]. However, most of the study on microalgal culture for wastewater treatment uti- lized wastewater after aeration and sedimentation process. Hence, wastewater treatment using microalgae are usually described as a secondary or tertiary treatment process. Unlike previous research, this study aim to evaluate the possibility of using primary wastewater from aeration tank containing high suspended solids (MLSS) from instant noodle factory as the whole nutrients source for microalgal growth. This would lead to an alternative way of the future wastewater treatment using microalgal cultivation in photobioreactor.

\section{Materials and Methods}

\subsection{Microalgal Strains}

Scenedesmus sp. was obtained from the culture collection of Center of Excellence for Marine Biotechnology, Chulalongkorn University. Stock culture of Scenedesmus sp. was kept in BG-11 medium containing (g/L): $\mathrm{K}_{2} \mathrm{HPO}_{4} \cdot 3 \mathrm{H}_{2} \mathrm{O}, 0.04 ; \mathrm{MgSO}_{4} \cdot 7 \mathrm{H}_{2} \mathrm{O}, 0.075 ; \mathrm{CaCl}_{2}$.

Received May 30, 2014 Accepted August 26, 2014

$\uparrow$ Corresponding author

E-mail: sorawit@biotec.or.th

Tel: +66-81-846-2682 Fax: +66-2-2547-7680 medium, provided the original work is properly cited.

Copyright (C) 2014 Korean Society of Environmental Engineers 
$2 \mathrm{H}_{2} \mathrm{O}, 0.036$; citric acid, 0.006; ferric ammonium citrate, 0.006; EDTA, 0.001; $\mathrm{NaNO}_{3}, 1.5 ; \mathrm{Na}_{2} \mathrm{CO}_{3}, 0.02$; trace metal mix A5, 1.0 $\mathrm{mL}$ which consisted of (g/L) $\mathrm{H}_{3} \mathrm{BO}_{3}, 2.86 ; \mathrm{MnCl}_{2} \cdot 4 \mathrm{H}_{2} \mathrm{O}, 1.81 ; \mathrm{ZnSO}_{4}$. $7 \mathrm{H}_{2} \mathrm{O}, 0.222$; $\mathrm{NaMoO}_{4} \cdot 2 \mathrm{H}_{2} \mathrm{O}, 0.39$; $\mathrm{CuSO}_{4} \cdot 5 \mathrm{H}_{2} \mathrm{O}, 0.079$; and $\mathrm{CoCl}_{2}$. $6 \mathrm{H}_{2} \mathrm{O}, 0.05$ [4]. Microalgal was incubated under continuous light $(5,000 \operatorname{lux})$ at $25 \pm 1^{\circ} \mathrm{C}$ with continuous aeration.

\subsection{Wastewater Collection}

Wastewater was taken from the wastewater treatment plant of instant noodle factory in Bangkok. The main organic waste fraction was from wheat starch, cooking oil and seasoning residue. MLSS collected form aeration tank and effluent collected from final sedimentation tank were chosen for this study (Fig. 1). Wastewater was transported to the laboratory and kept frozen at $-20^{\circ} \mathrm{C}$ prior to use. To prepare the culture media, frozen wastewater was defrosted to room temperature and used without sterilization. Parameters of wastewater including $\mathrm{pH}$, total nitrogen (TN), ammonia $\left(\mathrm{NH}_{3}-\mathrm{N}\right)$, nitrate $\left(\mathrm{NO}_{3}{ }^{-}\right)$, nitrite $\left(\mathrm{NO}_{2}{ }^{-}\right)$, total phosphorus (TP), phosphate $\left(\mathrm{PO}_{4}{ }^{3-}\right)$, total suspended solids (TSS) and chemical oxygen demand (COD) were analyzed according to standard methods $[5,6]$.

\subsection{Screening of Optimal Wastewater Dilution for Microalgal Growth}

Each MLSS and effluent sample was filtered with GF/C filter to remove suspended solids and diluted with deionized water into four concentrations i.e. $100 \%$, $75 \%$, $50 \%$, and $25 \%$ for investigating effect of various nutrients concentration that able to support microalgal growth. BG11 medium was assigned as control. The screening was performed using 24 wells microplate (tissue culture plate) filled with 1800 microliters of wastewater and then inoculated with 200 microliters (10\% inoculation) of Scenedesmus sp. stock culture. The microplate was incubated under high humidity condition to minimize evaporation. The experiment was conducted with four replicates (four wells) for each concentration. Growth of the microalgae was determined by measuring $\mathrm{OD}_{680} \mathrm{~nm}$ daily using microplate spectrophotometer (Power Wave XS2) within 10 days in order to estimate microalgae growth.

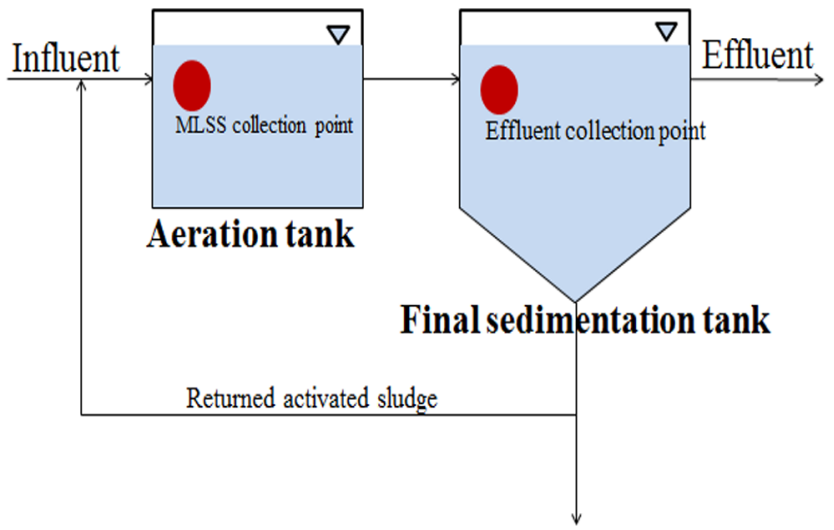

Fig 1. Wastewater collections from activated sludge wastewater treatment process of wan thai foods industry co., Itd.

\subsection{Cultivation of Scenedesmus sp. using Wastewater from Instant Noodle Factory}

Ten days-batch experiments were conducted using 2,000 $\mathrm{mL}$ Duran bottle as the culture vessel. Culture condition was $33.2 \pm 0.7^{\circ} \mathrm{C}$ under continuous light at approximately 5,000 lux. Aeration was provided continuously at $48 \mathrm{~mL} / \mathrm{s}$ using atmospheric air from an aquarium air pump through air sparger. All batch cultivations were carried out in triplicate. Duran bottles were filled with 1,800 $\mathrm{mL}$ of wastewater and $200 \mathrm{~mL}$ of Scenedesmus sp. stock culture. MLSS and effluent without dilution were used as the culture medium, and the BG11 medium was assigned as a control.

\subsection{Microalgal Growth Measurement}

The microalgal cell density was counted daily under microscope observation using a haemocytometer. Biomass (dry weight) was calculated using linier relationship between dry weight biomass and cell density counted with haemacytometer according to the equation:

$$
\begin{aligned}
& \text { Dry weight }(\mathrm{mg} / \mathrm{L}) \\
& \quad=\left(\text { Cell density }\left(10^{4} \mathrm{cell} / \mathrm{mL}\right)+7.2328\right) / 0.2945
\end{aligned}
$$

A growth curve was plotted between biomass or cell concentration and time. Specific growth rate $(\mu)$ was calculated with the following equation:

$$
\mu=\frac{\ln N 2-\ln N 1}{T 2-T 1}
$$

Where $\mathrm{N} 1$ and $\mathrm{N} 2$ are cell densities at times $\mathrm{T} 1$ and $\mathrm{T} 2$ respectively.

\section{Results and Discussion}

\subsection{Growth of Scenedesmus sp. in Wastewater}

Characteristics of wastewater from instant noodle factory and BG11 medium for Scenedesmus sp. cultivation were showed in Table 1. Nutrients concentration in MLSS was higher than effluent water due to the treatment processes. Growth curves of Scenedesmus sp. in various percentage of wastewater were shown in Fig. 2. The results indicated that both wastewaters without dilution provided the highest growth rate of Scenedesmus sp. Specific growth rate during the second day of algal cultivation with $100 \%$ MLSS and $100 \%$ effluent were $1.63 \pm 0.11$ day $^{-1}$ and $1.57 \pm 0.16$ day $^{-1}$, respectively. Both specific growth rates were significantly ( $\mathrm{p}<0.05$ ) higher than BG11 medium $\left(1.08 \pm 0.14\right.$ day $^{-1}$ ). However, Scenedesmus sp. in treatments entered stationary phase after day 4 while algal cultured in BG11 was end up with higher cell density. Min et al. also demonstrated that high concentration of nutrients in wastewater can support the highest growth performance of the microalga Chlorella sp. [7]. Therefore wastewater from instant noodle factory without dilution was selected for further study. 
Table 1. Physical and Chemical Characteristics of Wastewater from Instant Noodle Factory and BG11 Medium

\begin{tabular}{lccc}
\hline \multicolumn{1}{c}{ Parameter (Unit) } & \multicolumn{1}{c}{ Medium } & BG11 \\
\cline { 2 - 4 } pH & $7.17 \pm 0.06$ & $7.43 \pm 0.27$ & $7.68 \pm 0.13$ \\
Total nitrogen (mg N/L) & $189.87 \pm 14.80$ & $68.74 \pm 11.90$ & $268.62 \pm 12.88$ \\
Soluble total nitrogen (mg N/L) & $32.09 \pm 7.43$ & $45.07 \pm 2.66$ & $228.04 \pm 22.92$ \\
Ammonia nitrogen (mg N/L) & $1.32 \pm 0.15$ & $1.24 \pm 0.10$ & $0.44 \pm 0.11$ \\
Nitrite (mg N/L) & $0.04 \pm 0.00$ & 0.00 & $0.06 \pm 0.00$ \\
Nitrate (mg N/L) & $44.81 \pm 3.63$ & $46.28 \pm 0.32$ & $260.36 \pm 6.94$ \\
Total phosphorus (mg P/L) & $5.93 \pm 0.37$ & $3.13 \pm 0.13$ & $3.86 \pm 0.17$ \\
Soluble total phosphorus (mg P/L) & $0.40 \pm 0.07$ & $1.33 \pm 0.07$ & $1.50 \pm 0.05$ \\
Phosphate (mg P/L) & $1.82 \pm 0.38$ & $1.10 \pm 0.04$ & $1.94 \pm 0.62$ \\
Total suspended solids (mg/L) & $5500.00 \pm 244.34$ & $126.67 \pm 5.77$ & $106.67 \pm 28.87$ \\
Chemical oxygen demand (mg/L) & $3366.00 \pm 200.92$ & $198.00 \pm 6.51$ & $168.67 \pm 4.62$ \\
Soluble chemical oxygen demand (mg/L) & $367.16 \pm 8.08$ & $148.88 \pm 10.81$ & $59.41 \pm 4.60$ \\
\hline
\end{tabular}
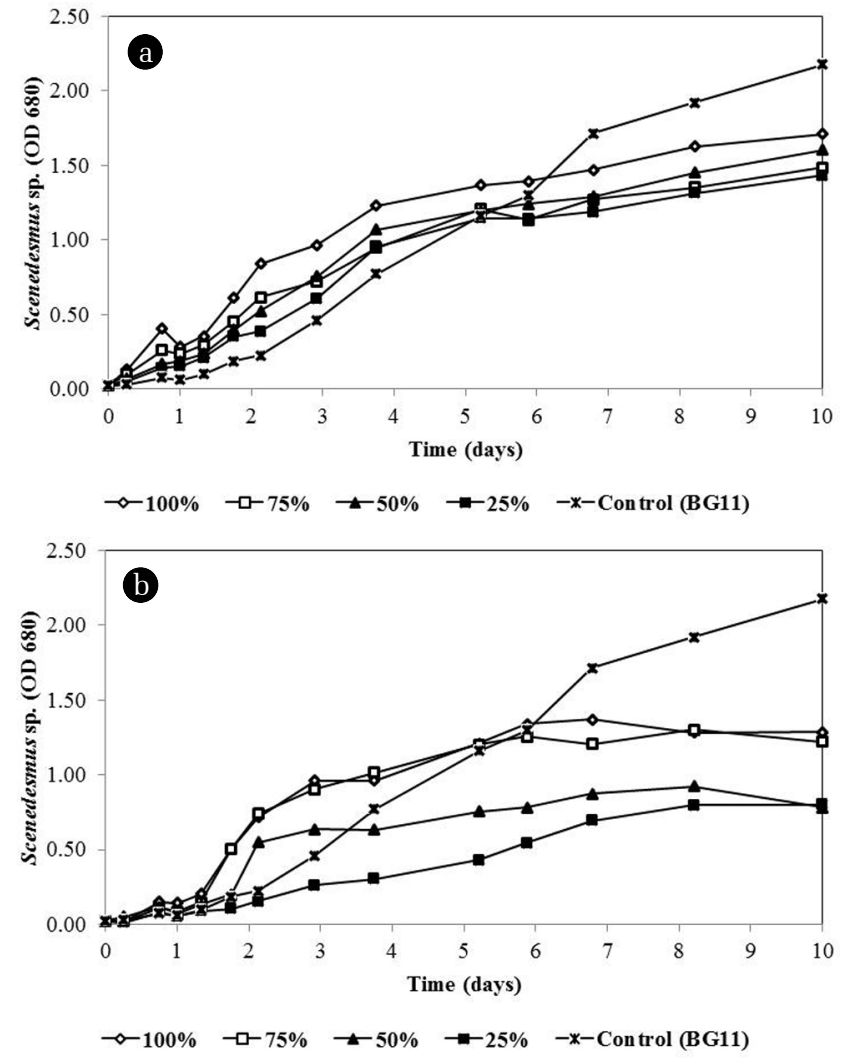

Fig. 2. Growth curve of scenedesmus sp. using various percentage of wastewater from instant noodle factory as a medium in 24 wells microplate (a) MLSS (b) effluent.

\subsection{Scenedesmus sp. Cultivation using Undiluted Wastewater}

Fig. 3 illustrated that MLSS and effluent without dilution could be successfully used as the culture medium for Scenedesmus sp.. At the $4^{\text {th }}$ day of the experiment, microalgae in all media reach the maximum biomass of $344.16 \pm 105.60 \mathrm{mg} / \mathrm{L}$ and $512.89 \pm 86.93 \mathrm{mg} / \mathrm{L}$ for MLSS and effluent, respectively. The data obtained in this

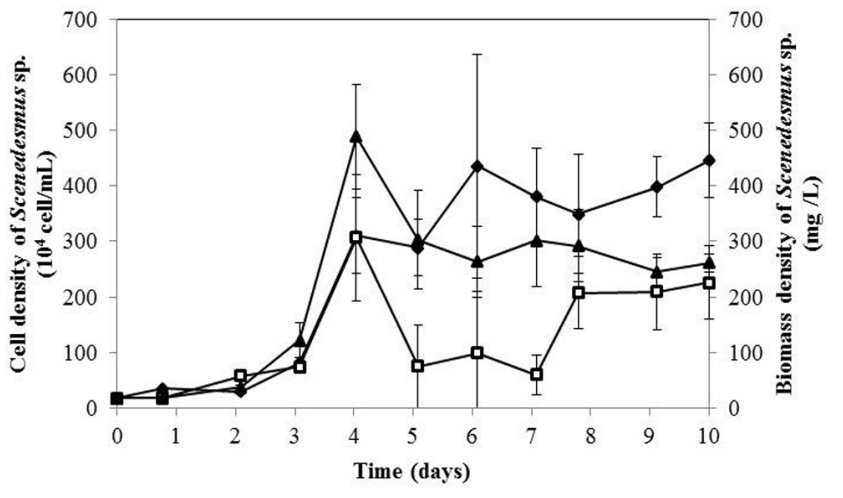

$\rightarrow$ Con trol (BG11) $\rightarrow$-MLSS $\rightarrow$ Effluent

Fig. 3. growth curve of Scenedesmus sp. using wastewater from instant noodle factory as a medium in $2,000 \mathrm{~mL}$ duran bottle at $33.2 \pm 0.7^{\circ} \mathrm{C}$ under continuous light and aeration.

experiment was slightly higher than previous report which was $356 \pm 15.4 \mathrm{mg} / \mathrm{L}$ of Scenedesmus sp. AMDD cultivated in municipal wastewater [8]. Growth performance was described in Table 2. Since there was no significant $(\mathrm{p}<0.05)$ difference on growth and biomass of all treatments and control, it could be stated that both wastewater types had a potential to be used as whole nutrients supplement for microalgal cultivation.

Concentrations of inorganic nutrients during algal cultivation were shown in Fig. 4. Total ammonia nitrogen was high in MLSS cultivation because of organic nitrogen breakdown (ammonification) which released ammonia into the medium. Park et al. reported that ammonium up to $100 \mathrm{ppm} \mathrm{NH}_{4}-\mathrm{N}$ did not inhibit growth of Scenedesmus sp. [9] so ammonia concentration in this experiment was within the safety range for the alga. Accumulation of nitrite in control culture was due to the lack of nitrite oxidizing bacteria and denitrification process could not occur in high oxygen condition in algal cultures. According to low level of phosphate in both wastewaters, at day 4 phosphates in MLSS and effluent almost depleted (Fig. 4(d)). Moreover, cultivation of Scenedesmus sp. had capable to reduce total COD by $71.85 \%$ and $39.89 \%$ for 
Table 2. Growth Performance of Scenedesmus sp. Using Wastewater as a Medium

\begin{tabular}{ccccc}
\hline Medium & $\begin{array}{c}\text { Initial biomass } \\
(\mathrm{mg} / \mathrm{L})\end{array}$ & $\begin{array}{c}\text { Maximum biomass } \\
(\mathrm{mg} / \mathrm{L})\end{array}$ & $\begin{array}{c}\text { Duration to maximum biomass } \\
(\text { day })\end{array}$ & $\begin{array}{c}\text { Specific growth rate } \\
(\text { day-1) }\end{array}$ \\
\hline Control (BG11) & $76.82 \pm 0.18^{\mathrm{NS}}$ & $463.25 \pm 185.58^{\mathrm{NS}}$ & 6 & $1.08 \pm 0.16^{\mathrm{NS}}$ \\
MLSS & $76.97 \pm 0.26^{\mathrm{NS}}$ & $344.16 \pm 105.60^{\mathrm{NS}}$ & 4 & $1.08 \pm 0.11^{\mathrm{NS}}$ \\
Effluent & $77.08 \pm 0.41^{\mathrm{NS}}$ & $512.89 \pm 86.93^{\mathrm{NS}}$ & 4 & $1.09 \pm 0.08^{\mathrm{NS}}$ \\
\hline
\end{tabular}

Remark: " Data with different letter in the same column for each treatment were a significantly difference $(\mathrm{p}<0.05)$; $\mathrm{NS}=$ non significant $(\mathrm{p}<0.05)$.
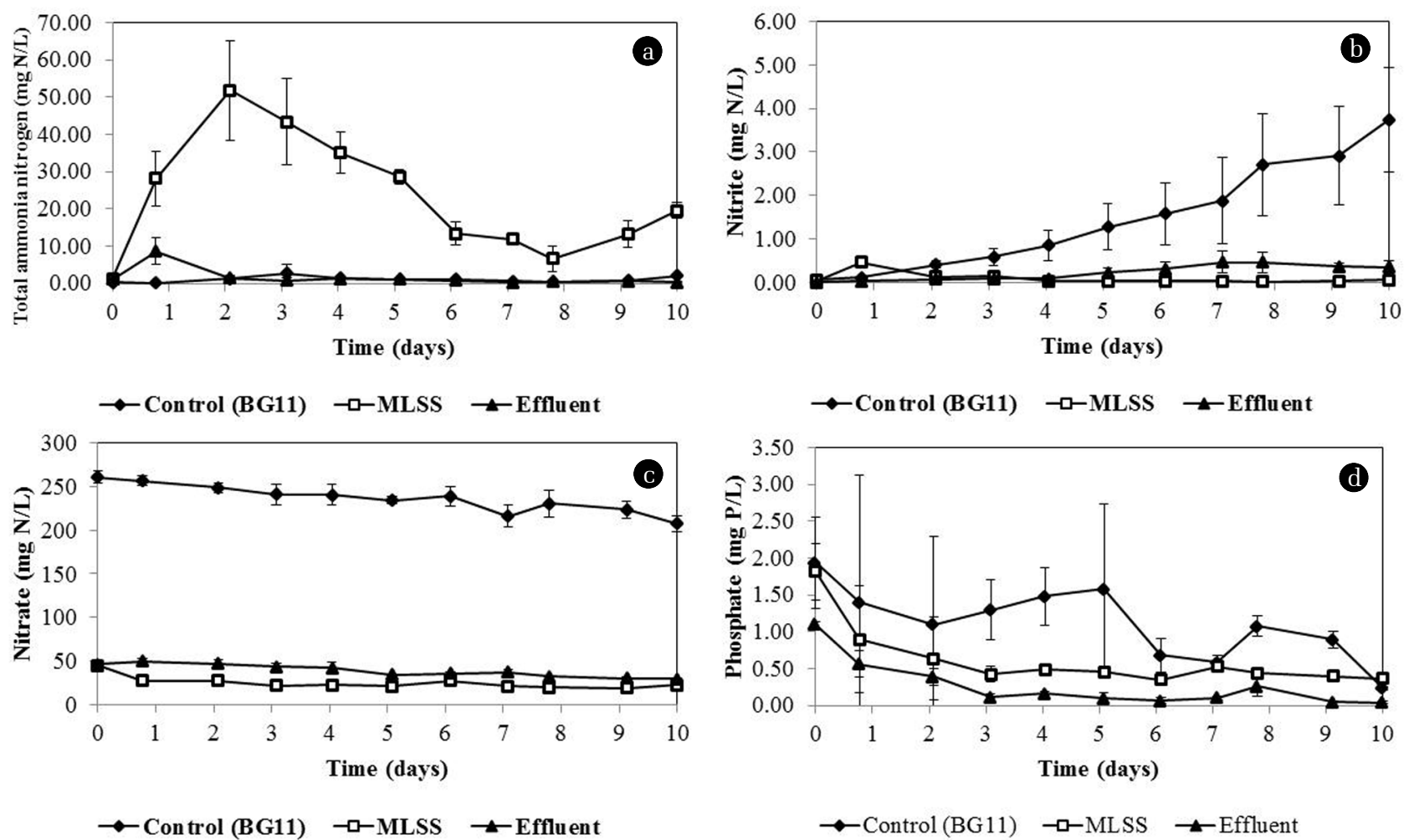

Fig. 4. Inorganic nitrogen and inorganic phosphorus profile during Scenedesmus sp. cultivation in 2,000 $\mathrm{mL}$ duran bottle (a) total ammonia nitrogen (b) nitrite (c) nitrate and (d) phosphate.
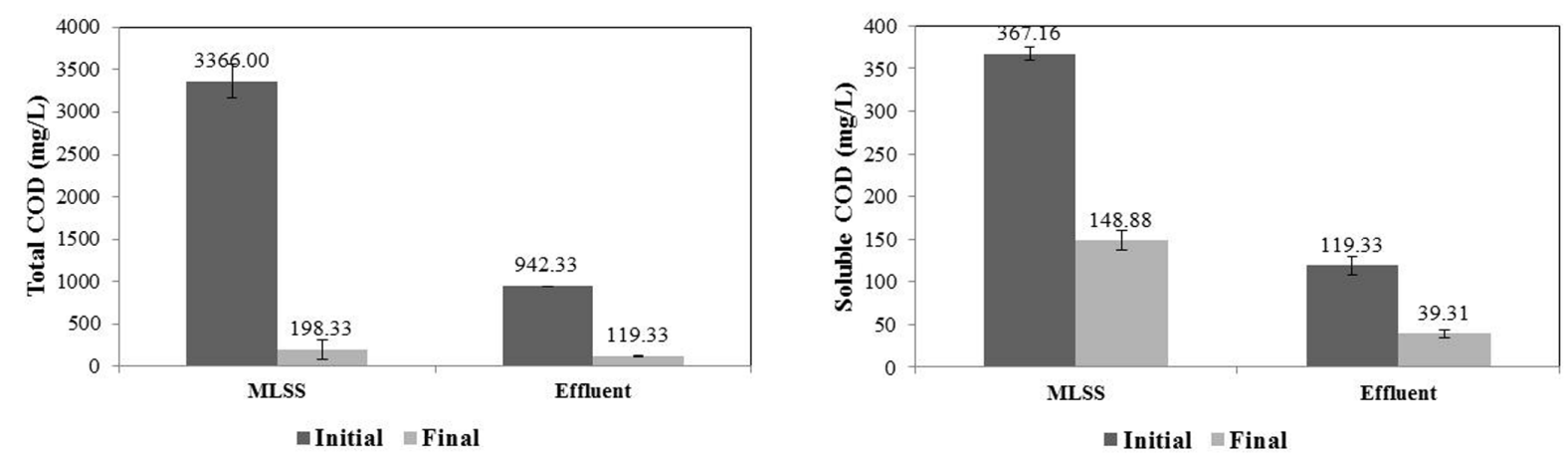

Fig. 5. Chemical oxygen demand (COD) change during the initial and final of microalgae cultivation in wastewater from instant noodle factory (a) total COD (b) soluble COD.

MLSS and effluent respectively. On the other hand, reduction of soluble COD was $67.49 \%$ and $73.37 \%$ for MLSS and effluent respectively (Fig. 5). In general, reduction of COD in typical wastewater treatment is generally the results from bacterial decomposition. COD removal by natural bacteria in this experiment was expected because the wastewater was used without sterilization. However, 
as Scenedesmus sp. can be grown in mixotrophic mode using organic carbon, COD removal found in this study was probably due to both algal and bacterial activities.

\section{Conclusions}

Results from this study illustrated that wastewater from instant noodle factory can be used as a whole source of nutrients for the cultivation of microalga Scenedesmus sp. for biomass production and wastewater treatment. MLSS Wastewater without dilution containing 5,500 $\mathrm{mg} \mathrm{SS} / \mathrm{L}$ and $189 \mathrm{mg}$ total-N/L can promote high growth rate of Scenedesmus sp. due to the high residual nutrients. Both MLSS and effluent exhibited similar capability to be used as culture media for microalgae. However, according to cost of wastewater treatment MLSS will be chosen for further investigation. This will lead to the future development of wastewater treatment using photobioreactor.

\section{Acknowledgements}

The authors would like to thank Wan Thai Foods Industry Co., Ltd and TAIST-Tokyo Tech. The Analytical equipment as spectrophotometer is provided by the Government Stimulus Package 2 (TKK2555) under the project for Establishment of Comprehensive Center for Innovative Food, Health Products and Agriculture, Chulalongkorn University. Other equipments and facilities were provided by the Center of Excellence for Marine Biotechnology, Department of Marine Science, Faculty of Science, Chulalongkorn University, Thailand.

\section{References}

1. Park JBK, Craggs RJ, Shilton AN. Wastewater treatment high rate algal ponds for biofuel production. Bioresour. Technol. 2011;102:35-42.

2. Rawat I, Ranjith Kumar R, Mutanda T, Bux F. Dual role of microalgae: phycoremediation of domestic wastewater and biomass production for sustainable biofuels production. Appl. Energy 2011;88:3411-3424.

3. Honda R, Boonnorat J, Chiemchaisri C, Chiemchaisri W, Yamamoto K. Carbon dioxide capture and nutrients removal utilizing treated sewage by concentrated microalgae cultivation in a membrane photobioreactor. Bioresour. Technol. 2012;125 59-64.

4. Zhou W, Min M, Li Y, Hu B, Ma X, Cheng Y, Liu Y, Chen $\mathrm{P}$, and Ruan R. A hetero-photoautotrophic two-stage cultivation process to improve wastewater nutrient removal and enhance algal lipid accumulation. Bioresour. Technol. 2012;110:448455.

5. Strickland JDH, Parsons TR. A practical handbook of seawater analysis. (2nd ed.). Department of Fisheries and the Environment, Canada; 1972.

6. APHA. Standard method for the examination of water and waste water (21st ed.) American Public Health Association, Washington DC; 2005.

7. Min M, Wang L, Mohr MJ, Hu B, Zhou W, Chen P, Ruan R. Cultivating Chlorella sp. in a pilot-scale Photobioreactor using centrate wastewater for microalgae biomass production and wastewater nutrient removal. Appl. Biochem. Biotechnol. 2011;165:123-137.

8. McGinn PJ, Dickinson KE, Park KC, Whitney CG, MacQuarrie SP, Black FJ, Frigon JC, Guiot SR, O'Leary SJB. Assessment of the bioenergy and bioremediation potentials of the microalga Scenedesmus sp. AMDD cultivated in municipal wastewater effluent in batch and continuous mode. Algal Research 2012; 1:155-165.

9. Park J, Jin HF, Lim BR, Park KY, Lee K. Ammonia removal from anaerobic digestion effluent of livestock waste using green alga Scenedesmus sp. Bioresour. Technol. 2010;101:8649-8657. 